\title{
Two New Species of Thalloid Hepaticae from Japan.
}

\author{
By
}

\section{Yoshiwo Horikawa.}

With 3 Text-figures.

Received March 30, 193\%.

Plagiochasma nipponica IORIKnWA, sp. nov.

Dioica. Planta mediocris, virens, margine et postice purpurea, dense caespitosa. Frons usque ad $20 \mathrm{~mm}$. longa, $3 \mathrm{~mm}$. lata, rigila, ex apice repitito innovata; costa humillima, in sectione transverse fronde subduplo humilior, plus 3.5 plo angustior, medio ca. 8-10 cellulas crassa. Stratum anticum valde cavernosum, cavernae leviter amplae. Stomata parva convexa, poro minuto, cellulis triseriatis circum(lato; cellulae epidermidis fere unistratae, trigonis bene incrassatae. Squamae posticae parvae, intense purpureae, oblique late semilunatae, sensim in appendiculum angustatae, appendiculis ad 2 vel 3 , non constrictis, anguste lanceolatis, ca. $0.5 \mathrm{~mm}$. longo, 0.0.5 mm. lato, margine papulosis. Carpocephala stubsessilia, paleis

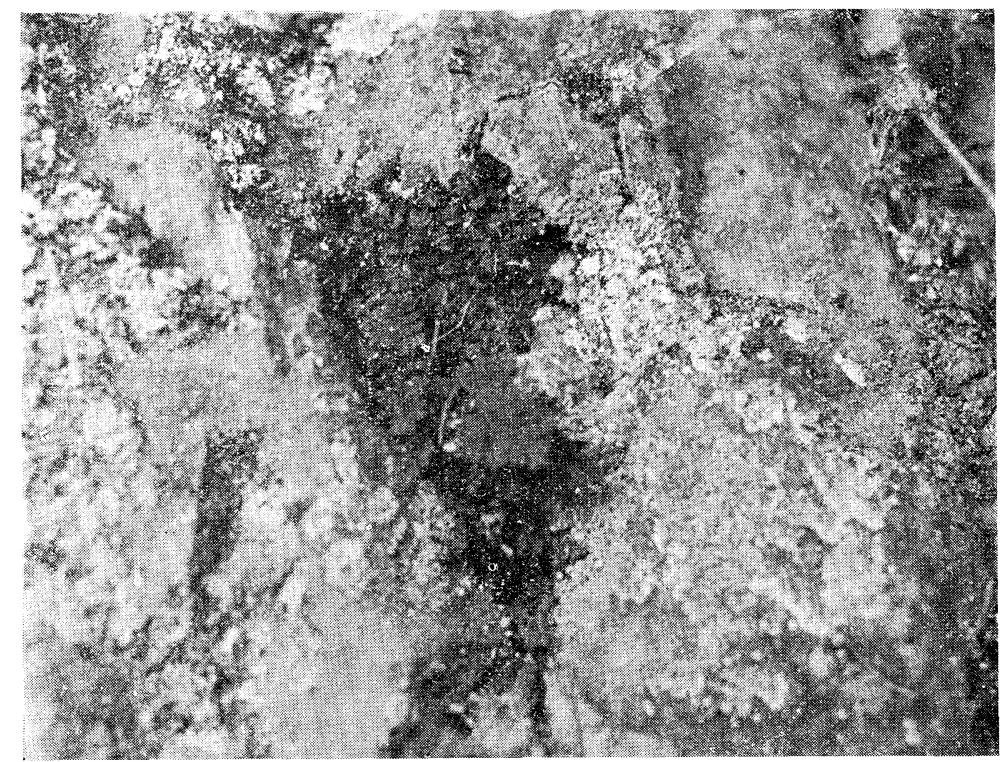

Fig. 1. Natural habit of Plagiochasma nipponica HoRIKAws, growing with Dryopteris crenata O. Kun'rze. 


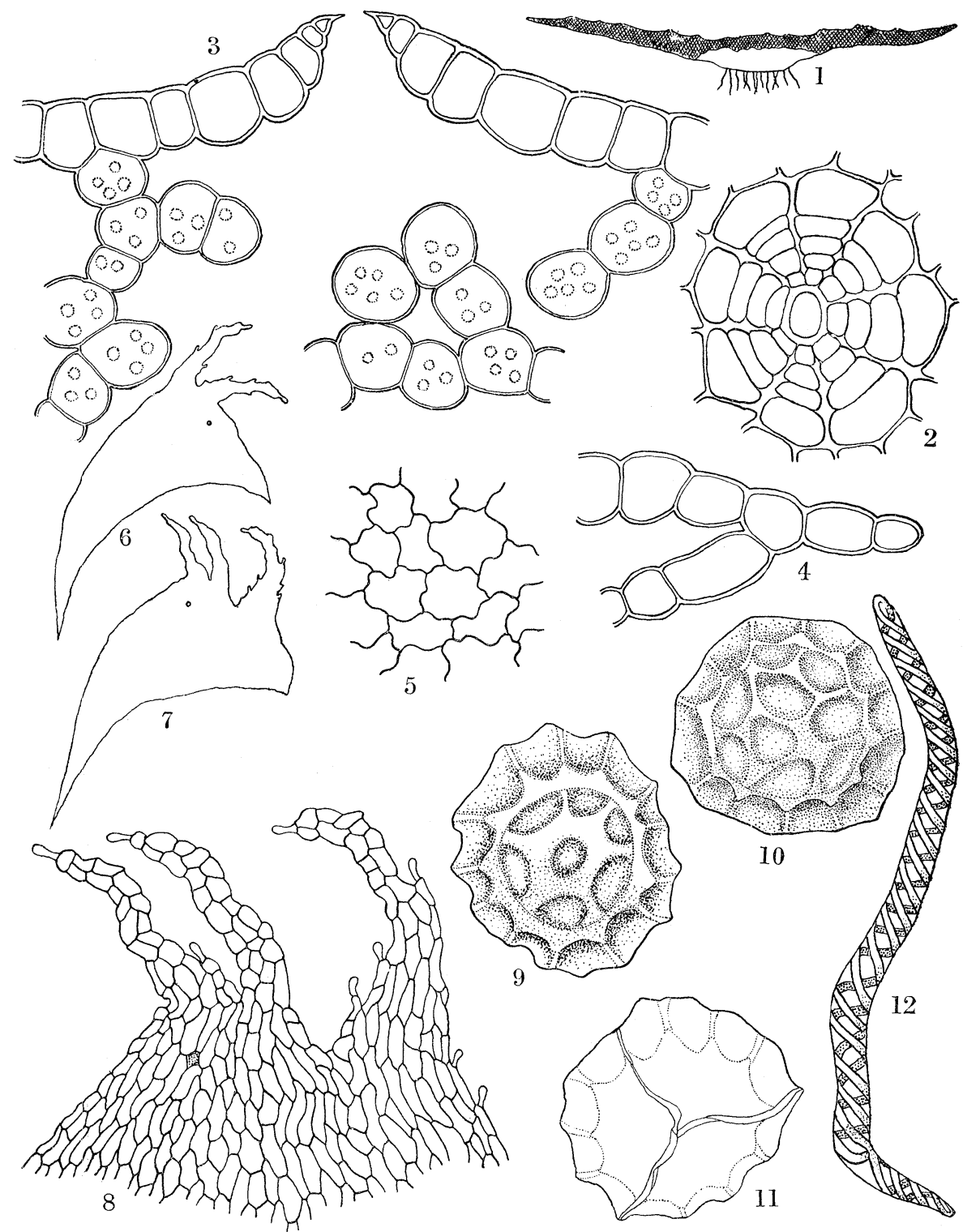

Fig. 2. Plagiochasma nipponica HoRIKawa. 1. Cross-section of thallus, $\times 12$. 2. Pore, surface view, $\times 300$. 3. Pore, cross-section, $\times 350$. 4. Marginal part of thallus, cross-section, $\times 350$. 5. Cells from ventral compact tissue, $\times 350$. 6, 7. Ventral scales, $\times 24$. 8. Appendages, $\times 78.9,10,11$. Spores, $\times 300.9,10$. Spherical faces. 11. Plane face. 12. Elater, $\times 270$.

numerosis, purpureis, anguste lanceolatis ; capitula uni- vel bilobata, vertice lunatim exciso-subcornuta. Sporae $110 \mu$, late alato-reticulatae, fusco- 
brunneae, minute verruculosae. Elateres flavescentes, $330 \mu$ longi, $11 \mu$ lati, bi- vel trispiri, spiris anguste tortis.

Hab. On thin soil among limestone-cracks.

Honshiu: Taishaku-kyô, prov. Bingo (Y. Horikawa, Oct. 3, 1936-typus). Shikoku: Ogawa-mura, prov. Tosa (Y. Honikawa, March 28, 1924).

Riccardia pellioides IIorIKawa, sp. nov.

Dioica ; major, latissima, tenera et membrana, pallide virens, densissime intricatim stratificata. Frons ad $40 \mathrm{~mm}$. longa, $8 \mathrm{~mm}$. lata, plana, margine undulata, repitito-furcata, furcis divergentibus, $15 \mathrm{~mm}$. longis, $5 \mathrm{~mm}$. latis; costa plana, latissima, 7-9 cellulas crassa, sensim in alas transiens; cellulae internae frondis corticalibus multo majores perlucentes. Calyptra maxima, cylindrica, 15-18 mm. longa, plus $1 \mathrm{~mm}$. crassa, sublaevis vel pauci-villosa,

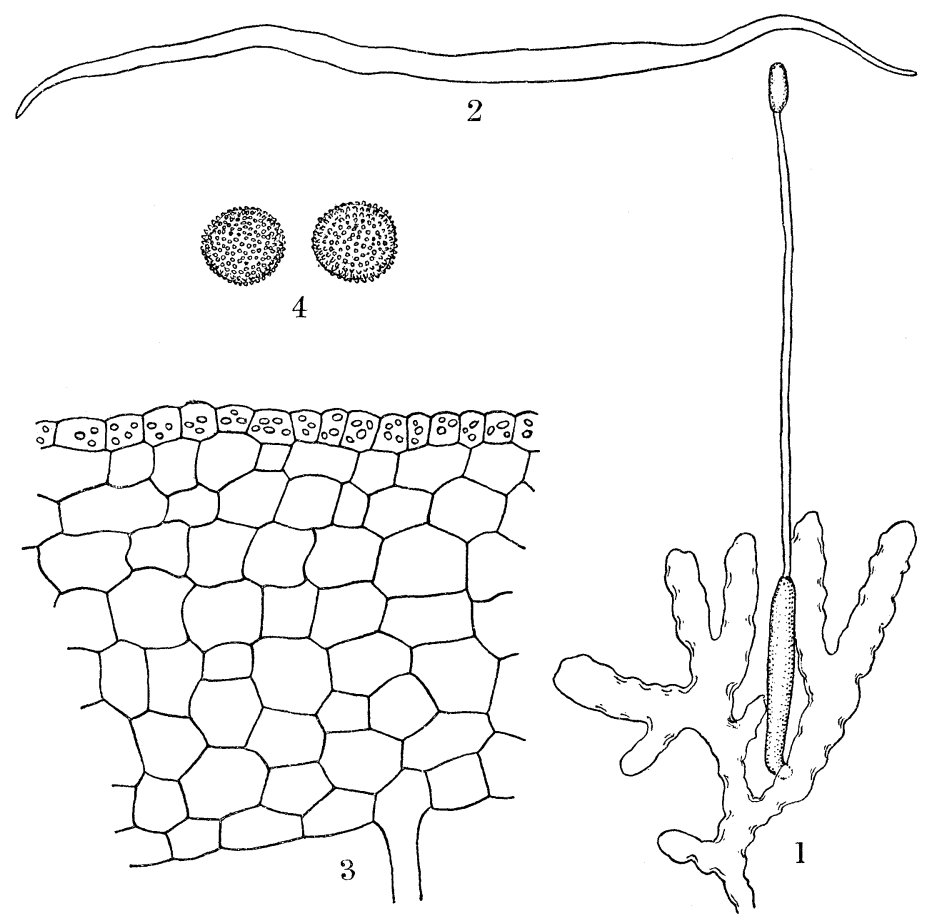

Fig. 3. Riccardia pellioides MonIKaws. 1. Female plant with calyptrat and sporophyte, in nat. size. 2. Cross-section of thallus, $\times 12$. 3. Middle part of ditto, $\times 130$. 4. Spores, $\times 330$.

apice subumbonata. Seta longissima, ad $40 \mathrm{~mm}$. longa. Sporae ad $26 \%$ in diam., viridi-brunneolae minute papillatae. Elateres ad $280 \mu$ longi et $8 \mu$ lati, rufescenti-brunnei, attenuati, monospiri, laxe torti.

$H a b$. On wet sandy soil along the stream. 
Honshiu: Mitaki, prov. Aki (Y. Horıknwa, March 10, 1922); ibidem (S. Tatuno, March 8, 1937-typus in Herb. Hirosima Univ.).

Botanical Institute, Hirosima University.

\title{
Pulvinus als Hauptsitz der in den Primärblättern entstehenden Potentialänderungen bei Canavalia ensiformis DC.
}

\author{
Von
}

\section{Yasuke Yamaguti.}

Mit 2 'Textfiguren.

Eingegangen am 30. März 193\%.

Vor Jahren habe ich zur Orientierung der elektrischen Potentialänderungen, die bei den Schlafbewegungen der Primärblätter von Canavalia ensiformis DC. an genanntem Organ vorkommen, einige Versuche gemacht, um dadurch, von einer bisher wenig beachteten Seite, ïbor die inneren Vorgänge bei genannter Bewegung einen Einblick erhalten zu können ${ }^{1)}$. Damals ergab sich, dass in den sich tagesperiodisch bewegenden Primärblättern damit irgendwic verkoppelte, parallellaufende Potentialänderungen zu erkemnen sind, und dass je nach der Morgen- oder Abendphase der Bewegung sogar die Inversion der relativen Vormeichen des Potentials beobachtet werden kann. Diese Potentialänderungen wurden mit dem Röhrenvoltmeter in Verbindung mit einem kleinen Permanentmagnet-Saitengalvanometer Edemimanns oder einem Millivoltmeter (SIEMENs, $2288 \mathrm{Ohm}$ ) registriert oder ermittelt, indem die unpolarisierbaren Elektroden an die verschiedenen Stellen der Versuchspflanze gelegt wurden. Dass sich die somit ermittelten Potentialänderungen auf die Oberfläche der betreffenden Stellen der Versuchspflanze beziehen und nicht immer über die wahren Zustandsänderungen im Innern derselben eine Auskunft erteilen können, war mir schon damals, vor der Kritik BünNings $(1934)^{2)}$, bewusst. So habe ich mich in den darauffolgenden Jahren zunächst bemüht, passende Elektroden zu finden, die durch Einstechen in

1) Yamagutr, Y.: Üher elektrische Potentialveränderungen an periodiseh sich bewegenden Primärblättem von Canavalia ensiformis JC. Bot. Marg. Tokyo, 46: 216$222,1932$.

1) Bünning, E.: Die Mechanik der tagesperiodischen Variationshewegungen von Phaseolus multiflorus. Jahrb. wiss. Bot., 79: 191-230, 1934. 